\title{
Content interaction in online university courses: The start@unito project
}

\section{Stefania Cicillini, Daniela Salusso}

Dipartimento di Lingue e Letterature Straniere e Culture Moderne, Università degli Studi di Torino, Italia.

\begin{abstract}
The growing number of online courses offered by many universities worldwide is reshaping the traditional delivery of knowledge. This study tries to combine e-learning and the learning principles of language and linguistics. Drawing on the experience of the start@unito project at the University of Torino, which this year also offers language and linguistics courses, we tackle one of the main problems of online education, namely that of interaction. This study tries to combine e-learning and the learning principles of language and linguistics, focusing on the three types of interaction proposed by Moore (1989): learner-learner, learner-instructor, learner-content interactions. Specifically, we concentrate on the various ways in which learners may interact with the content in asynchronous untutored online university courses. Starting from the assumption that all the language and linguistics courses need a great deal of interaction, in order to be beneficial to students, it emerges that the application of pedagogical approaches and a careful instructional design of the courses may facilitate a more effective interaction with the content of the object of study.
\end{abstract}

Keywords: Content Interaction; E-learning; Online Interaction; Online Language and Linguistics; Online Teaching, Open Online University Courses. 


\section{Introduction}

Nowadays a growing number of universities is offering their students new web-based learning environments in many subject areas and learning foreign languages and linguistics is not excluded from this phenomenon. The University of Torino has recently embarked on a new project called start@unito (Bruschi et al., 2018), which already offers 20 online open asynchronous courses in several disciplines such as Philosophy, History, Sociology, Physics, Mathematics, Informatics, Economics. In the spring 2019, 30 additional courses will become available, including 19 courses held in English, such as International Law, Business Law, Private Law, Macroeconomics, Marketing, Developmental Neurobiology, Mathematical Modeling and 6 language and linguistics ones (English, French, German, Portuguese, Russian, and Spanish). Online education brings about new concerns regarding the management of the online environment such as the necessity to adopt new teaching methods, the issue of learners' engagement, motivation, self-discipline and autonomy and the problem of interaction which is undoubtedly the most critical one. The issue of interaction strongly emerged during the second phase of the project precisely because we found ourselves dealing with many courses involving the presence and the study of a foreign language. Since the start@unito open courses do not involve the presence of tutors or forums because of the very nature of open online education, which is available anytime anywhere, the aim of the present paper is to analyze how a peculiar form of interaction can take place, namely, the interaction with content.

Our research revolves around the following questions: how can the principles of e-learning help in the creation of academic courses? How can interaction be achieved in an online asynchronous untutored university course, especially in foreign languages and linguistics ones?

\section{Theoretical framework}

With the advancement of technology and the subsequent growth of online courses and internet-based learning, there has been the urgency to redesign the online courses' curriculum, materials and outcomes, along with the necessity to reshape and adapt the standard techniques of teaching and learning in order to facilitate the incorporation of the pedagogical principles of teaching in web-based classes (Govindasamy, 2002). One of the main controversies is the lack of face-to face interaction, an issue that becomes even more pressing when language learning is involved. Nowadays, we are used to social media and to the fact that virtual interaction may replace the direct one but reshaping interaction in open online courses, which also lack the social dimension of forums and virtual tutoring, is not an easy task. The online courses offered at the University of Torino are not merely language courses, as we will explore more in detail in the next chapter, but the interactional 
factor has been brought to our attention especially by professors of language and linguistics. Language learning theories, in fact, have always stressed the importance of interaction in the process of language learning. Together with instructional design, the application of some language theories such as constructivism, social constructivism, constructionism and the most recent connectivism may be helpful to create online courses, apply pedagogical approaches and provide learners with effective tools; this may encourage learners to be more independent in their learning process and in doing so to easily interact with the content. (Papert, 1980; Govindasamy, 2002; Bell, 2009). Moreover, the online courses offered in linguistic disciplines are not merely language courses. They are language and linguistics courses which means that they involve both an implicit and an explicit study of language. Normally students receive linguistic guidance and feedback until they reach at least an A2-B1 level of linguistic competence - depending on the language studied - that will enable them to become independent users of that language and concentrate on the meta-reflection on it. In the online context, however, independence is required from the very beginning.

In an online environment learners and teachers are independent in terms of time and location, but are somehow connected and able to communicate by the use of technological devices and an internet connection. In fact, e-learning enables students to attend virtual classes, download study materials such as texts, handouts, videos and sit exams virtually, on their own and at their own pace (Ali, 2015). Thus, independence and autonomy are fundamental traits of learning online and are required for an effective interaction with the content. This is even truer when it comes to language learning, in fact, the above-mentioned process follows a specific path which differs from studying any other subject and for this reason it requires a specific methodology that may facilitate language flexibility, fluency and effectiveness in social, academic and professional contexts (Lantolf and Thorne, 2006; Vygotsky, 1978).

According to Chomsky, learning a language is a process in which the learner is active and independent in the processes of acquisition, organization and memorization of information (Chomsky, 1980). Similarly, constructivism underlined the importance of learners' autonomy; in fact, the theory was mainly based on the assumption that learners should interpret the world and construct their own knowledge and understanding upon the foundation of their previous learning (Jonassen, 1991, Lightbown and Spada, 2006). However, the aforementioned approach considered learning as an individual and subjective process of learning without taking into account the external stimulus which may derive from interaction. Afterwards, this view was enriched by social constructivists who recognized that knowledge is an interactional experience and that learners construct their own understanding and knowledge through their social interactions in social contexts (Cochrane, 2014). Constructionism shares most of constructivism's view but emphasizes 
the importance of the context and the environment of learning and its social interactions, in order to have diverse opportunities to learn (Ackermann, 2004). In recent years, a new learning theory has emerged, named connectivism; it mainly stresses the importance of social interactions, connections and information sharing in the development of learners' knowledge and learning (Bell, 2009, Siemens 2005, Downes 2010).

These learning theories all support the importance of interaction, especially the social interactions that happen between learners in a collaborative learning environment but it emerges that few studies have paid specific attention to the interaction with the content. In 1989, Moore suggested three types of interaction that may influence learning in online environments: 1. learner-learner interaction, which takes place among the participants of a class; 2. learner-instructor interaction, which refers to the communication between teacher and students. 3. learner-content interaction, which is mainly based on the contact between learners and the materials, the content and the subject matter proposed. This type of interaction promotes students' independence and supports the social-constructive view of learning in which students' autonomy lets them build their own thoughts, perspectives and knowledge and promotes problem solving (Moore, 1989; Moore \& Kearsley, 1996; Anderson, 2003).

Although interaction has always been considered as a fundamental element of education, both in traditional and online courses it emerges that much research should be carried out with respect to the interaction with the content in online asynchronous courses. The experience with start@unito shows that interaction with the content does indeed happen; since it involves no human interaction and is therefore less spontaneous, it must be carefully planned during the phase of course design.

\section{The start@unito experience}

The start@ unito project of the University of Torino aims to promote open online university courses in various scientific, legal, economic, humanistic and linguistic disciplines to students of the last year of high school, both as a means to ensure a smooth transition from high school to university and as a way to contribute to global knowledge. The courses can also be taken by regular students who work, live far away, or simply wish to study at their own pace. In the first year of the project, only courses held in Italian were proposed. As said before, in the second year, which is still ongoing, 19 courses of scientific, legal and economic area held entirely in English and 6 language and linguistics courses are currently being developed.

Having to deal with the issue of language so prominently, the lack of human interaction became a problem we could not ignore. What is more, the online courses are designed to be open and worth 9 ECTS, while normally the students who enrol in the Department of 
Foreign Languages, Literatures and Modern Cultures also attend language assistantship courses, taught by mother-tongue or bilingual lecturers, along with the linguistics ones, taught by professors. The practical language lessons are organized in small classes attended by an average of 30 students, whereas the linguistics lectures held in a more traditional university class environment. Passing the language test is a prerequisite for taking the linguistics exam.

Of course, providing both the language and the linguistics training in one online course is proving quite challenging.

Drawing on the experience as instructional designer and assistant for the start@unito project, we have found out that many language professors have voiced concern about the lack of interaction available in the online open courses, which makes it difficult to monitor pronunciation, and spoken and written abilities. The majority of these courses start at a beginner A1 level (French, German, Portuguese, Russian, Spanish), whereas the English language and linguistics course starts at a minimum B1 level, so students already possess independence and autonomy at least at the language level. In addition, the linguistics course is taught fully in English, therefore it presupposes language knowledge, yet at the same time it is also a reflection on language. In other words, the linguistics component makes knowledge explicit and requires already a solid base of implicit knowledge (Hulstijn, 2005), thus involving conscious awareness and intention. The introductory linguistics course covers phonology, morphology, syntax, sociolinguistics, language history and academic writing. The challenge of the online courses is to put together these two aspects, the language and the linguistics ones, accounting for the three types of interaction that make language learning possible. In transferring the courses online, the main challenge instructional designers and professors had to face was precisely how to transform and adapt the different types of interaction to the online context, which does not involve the presence of tutors or forums.

As for the learner-learner interaction, it was previously pointed out that since one of the characteristics of open courses is unlimited enrolment, it would not be feasible to moderate comments and posts on blogs and forums. The learner-instructor interaction is also absent in a direct way; nevertheless, by designing the course according to the principles of multimedia learning (Mayer, 2005) and learning object theory (Bruschi and Perissinotto, 2003) the instructor makes the third type of interaction - the learner-content one - possible. Here we will focus on the third type of interaction, the learner-content one: in the online environment, content may refer to a variety of tools such as texts, handouts, recordings, videos, interactive pdfs, assignments, glossaries, quiz, online games, and external links to other resources. Before analyzing them in detail, it is important to point out that many instructors make the wrong assumption that students nowadays are highly proficient in using the available technologies. Technical competences should not be taken for granted 
and tutorials always provided to explain how to approach and interact with the contents of the course, otherwise content interactivity is lost.

In the start@unito project, the main tools used to provide interaction with the content are the following:

- Active learning: instead of simply delivering distance lectures, videos can be interspersed with questions and feedback, thus encouraging the learner to reflect on the content and interact with the video. In addition, providing bite-sized content in the form of short videos allows mobile learning, which in turn offers more interactivity options and facilitates learning anytime and anywhere. Allowing students to be active also promotes their engagement, in fact another interaction-inducing technique relies on the alternation of written content and interactive pdfs. Interactive pdfs are not obtained simply by adding navigation buttons; video, audio files and hyperlinks can be inserted in order to transform a passive reading activity in an opportunity to actively engage with the content and be exposed to different types of media, which may suit different types of learning styles.

- Personalization and feedback: first of all, the very nature of open courses, which suggests but does not prescribe a progression of navigation, provides students with the option of picking and choosing contents according to their needs. The courses are organized in multiple layers of complexity, and different paths are suggested to those who are only browsing through the courses for orientation, wishing to complete the course and get a certificate or enrol at the university and sit the exam. A further personalization option is adaptive feedback, a way to design automatic differentiated responses to a question so that students who make a mistake can receive step-by-step guidance in solving a problem (Barana et al., 2018). Adaptive feedback also has a role in promoting self-evaluation and self-correction and in preventing feelings of frustration and isolation, should students not be able to understand their own mistakes.

- Using authentic materials: the lack of peer interaction is replaced by the presence of external links to websites, authoritative Youtube channels, and other authentic materials that work as an invitation for students to see the course as a point of departure to take charge of their own learning and expand it. The use of authentic materials to support teaching is particularly apt in the case of language learning. The creation of authentic tasks (Herrington, 2006) and the consistent use of the L2 promote learner's involvement through the immersion into the target community of practice (Little, 2004), thus scaffolding the development of autonomy.

- Using authentic, situation-based tasks: if a task has real-world relevance, it has a higher chance of being perceived as useful by learners. Authentic tasks are usually associated with the social constructivist idea of meaningful interaction, which is 
enhanced by collaboration with peers (Woo et al., 2007). We would argue that meaningful interaction can also be obtained with the content, for example through the use of animations that use storytelling to simulate the real-class experience. For example, many start@unito courses make use of Vyond classroom-themed animations, featuring an animated teacher explaining a topic, asking or answering questions in a class. Learners can therefore identify with the students and reflect on meaningful questions and answers.

- Promoting students' engagement: interaction with content is directly linked with students' engagement. It can be improved by using "furnishing" techniques, such as adding music and compelling graphics to help boost learners' motivation and attention level; by lowering the degree of formality in order not to add another distancing element in an already distance course; by using gamification techniques to elicit motivation for excellence. Especially in language and linguistics courses, students need to be exposed to both the informal and the formal language, and to master both the everyday and the technical vocabulary. At the same time, although gamification is unsuitable for approaching a complex subject such as linguistics, it works extremely well for language learning, especially for those languages which start at an A1 level. These courses also alternate the use of students' L1 and L2, so that they have time to adapt to the L2 while grasping essential concepts in their L1. This may pose a limitation to the openness of the project, but it is counterbalanced by the presence of courses in many different disciplines held entirely in English, and therefore aimed at an international audience.

\section{Conclusions}

Although the proliferation of online education has received attention from scholars both from the theoretical and the practical perspective, there is still much work and research to be done in the field. Online courses of foreign languages and linguistics are especially complicated to deal with because of their inherent necessity to provide guidance to beginner learners who are not yet autonomous, and a certain degree of spoken and written interaction. We have tried to offer a glimpse of what has been done so far to ensure that the only possible form of interaction, namely content interaction, will really take place. Yet, the start@unito project is still under way, so we have to wait until its completion to gather more specific data, both on quality evaluation of instructional design and course development and on students' fruition and learning outcomes. 


\section{References}

Ackermann, E.K. (2004). Constructing knowledge and transforming the world. Chapter published in: A learning zone of one's own: Sharing representations and flow in collaborative learning environments [M. Tokoro and L. Steels (Eds.). Amsterdam, Berlin, Oxford, Tokyo, Washington, DC. IOS Press. Part1. Chapt 2. pp. 15-37.

Ali, A. S. (2015). The future of e-learning and tools in higher education. International Journal of Advances in Computer Science and Technology, 4(10), 161-165.

Bell, F. (2009). Connectivism: A network theory for teaching and learning in a connected world. Educational Developments, The Magazine of the Staff and Educational Development Association, 10(3).

Barana, A, Di Caro, L., Fioravera, M., Floris, F., Marchisio, M., Rabellino, S. (2018). Sharing system of learning resources for adaptive strategies of scholastic remedial intervention. In Proceedings of the 4th International Conference on Higher Education Advances (HEAd'18). Universitat Politècnica València. https://doi.org/10.4995/HEAD18.2018.8232

Bruschi, B., Perissinotto, A. (2003). Come creare corsi on line. Roma: Carocci.

Bruschi, B., Cantino V., Cavallo Perin R., Culasso, F., Giors, B., Marchisio M., (...), Scomparin, L. (2018). Start@unito: a Supporting Model for High School Students Enrolling to University (pp. 307-312). Presented at the IADIS International Conference Cognition and Exploratory Learning in Digital Age 2018. Retrieved from http://www.iadisportal.org/digital-library/startunito-a-supporting-model-for-highschool-students-enrolling-to-university

Chomsky, N. (1980). Rules and representations. Oxford, England: Basil Blackwell.

Cochrane, T. D. (2014). Critical success factors for transforming pedagogy with mobile Web 2.0. British Journal of Educational Technology, 45(1), 65-82. http://dx.doi.org:10.1111/j.1467-8535.2012.01384.x

Downes, S. (2010). New technology supporting informal learning. Journal of Emerging Technologies in Web Intelligence, 2(1), 27-33.

Govindasamy, T. (2002). Successful implementation of E-Learning; Pedagogical considerations. The Internet and Higher Education, 4, 287-299. doi: 10.1016/S10967516(01)00071-9

Herrington, J., Reeves, T. C. \& Oliver, R. (2006). Authentic Tasks Online: A synergy among learner, task and technology. Distance Education, 27(2), 233 - 247.

Hulstijn, Jan H. (2005). Theoretical and empirical issues in the study of implicit and explicit second language learning. Studies in Second Language Acquisition 27, 129-140

Jonassen, D. H. (1991). Objectivism versus constructivism: do we need a new philosophical paradigm? Educational Technology and Research and Development 39, 5-14

Lantolf, J. P., \& Thorne, S. L. (2006). Sociocultural Theory and He Genesis of Second Language Development. Oxford: Oxford University Press.

Lightbown P. L., Spada N. (2006) How languages are learned. Oxford: Oxford University Press.

Little, D. (2004). Constructing a theory of learner autonomy: Some steps along the way. In 
K. Mäkinen, P. Kaikkonen, \& V. Kohonen (eds.), Future Perspectives in Foreign Language Education (pp. 15-25). Oulu: Publications of the Faculty of Education in Oulu University 101.

Mayer, R. E. (2005). Cognitive Theory of Multimedia Learning. In R. E. Mayer (Ed.), The Cambridge handbook of multimedia learning (pp. 31-48). New York, NY, US: Cambridge University Press. http://dx.doi.org/10.1017/CBO9780511816819.004

Moore, M. G. (1989). Three types of interaction. The American Journal of Distance Education, 3(2), 1-6.

Moore, M.G. \& Kearsely, G. (1996) Distance Education: a systems view. Belmont, CA: Wadsworth.

Papert, S. (1980). Mindstrorms. Children, Computers and Powerful Ideas. New York: Basic Books

Vygotsky, L. S. (1978). Mind in society: The development of higher psychological processes Cambridge, MA: Harvard University Press.

Woo, Younghee, Reeves, Thomas C. (2007). Meaningful interaction in web-based learning: A social constructivist interpretation. Volume 10, Issue 1 (pp. 15-25) https://doi.org/10.1016/j.iheduc.2006.10.005 